\title{
Pneumothorax Risk Factors in Smokers with and without Chronic Obstructive Pulmonary Disease
}

\author{
Brian D. Hobbs ${ }^{1,2}$, Marilyn G. Foreman ${ }^{3}$, Russell Bowler ${ }^{4}$, Francine Jacobson ${ }^{5}$, Barry J. Make ${ }^{4}$, Peter J. Castaldi ${ }^{1,6}$, \\ Raúl San José Estépar ${ }^{7}$, Edwin K. Silverman ${ }^{1,2}$, Craig P. Hersh ${ }^{1,2}$; and the COPDGene Investigators
}

${ }^{1}$ Channing Division of Network Medicine and ${ }^{2}$ Division of Pulmonary and Critical Care Medicine, Department of Medicine, Brigham and Women's Hospital and Harvard Medical School, Boston, Massachusetts; ${ }^{3}$ Division of Pulmonary and Critical Care Medicine, Department of Internal Medicine, Morehouse School of Medicine, Atlanta, Georgia; ${ }^{4}$ Division of Pulmonary, Critical Care and Sleep Medicine, Department of Medicine, National Jewish Health, Denver, Colorado; and ${ }^{5}$ Department of Radiology; ${ }^{6}$ Division of General Internal Medicine and Primary Care, Department of Medicine, and 7 Surgical Planning Laboratory, Department of Radiology, Brigham and Women's Hospital and Harvard Medical School, Boston, Massachusetts

\section{Abstract}

Rationale: The demographic, physiological, and computed tomography (CT) features associated with pneumothorax in smokers with and without chronic obstructive pulmonary disease (COPD) are not clearly defined.

Objectives: We evaluated the hypothesis that pneumothorax in smokers is associated with male sex, tall and thin stature, airflow obstruction, and increased total and subpleural emphysema.

Methods: The study included smokers with and without COPD from the COPDGene Study, with quantitative chest CT analysis. Pleural-based emphysema was assessed on the basis of local histogram measures of emphysema. Pneumothorax history was defined by subject self-report.

Measurements and Main Results: Pneumothorax was reported in $286(3.2 \%)$ of 9,062 participants. In all participants, risk of prior pneumothorax was significantly higher in men (odds ratio [OR], 1.55; 95\% confidence interval [CI], 1.08-2.22) and
non-Hispanic white subjects (OR, 1.90; 95\% CI, 1.34-2.69). Risk of prior pneumothorax was associated with increased percent CT emphysema in all participants and participants with COPD (OR, 1.04 for each $1 \%$ increase in emphysema; 95\% CI, 1.03-1.06). Increased pleural-based emphysema was independently associated with risk of past pneumothorax in all participants (OR, 1.05 for each 1\% increase; 95\% CI, 1.01-1.10). In smokers with normal spirometry, risk of past pneumothorax was associated with non-Hispanic white race and lifetime smoking intensity (OR, 1.20 for every 10 pack-years; 95\% CI, 1.09-1.33).

Conclusions: Among smokers, pneumothorax is associated with male sex, non-Hispanic white race, and increased percentage of total and subpleural CT emphysema. Pneumothorax was not independently associated with height or lung function, even in participants with COPD.

Clinical trial registered with www.clinicaltrials.gov (NCT00608764).

Keywords: pneumothorax; chronic obstructive pulmonary disease; emphysema

(Received in original form May 30, 2014; accepted in final form September 18, 2014)

Supported by NIH grants T32 HL007427, R01HL094635, R01NR013377, P01HL105339, R01HL089897, and R01HL089856. The COPDGene project is also supported by the COPD Foundation through contributions made to an Industry Advisory Board composed of AstraZeneca, Boehringer Ingelheim, GlaxoSmithKline, Novartis, Pfizer, Siemens, and Sunovion. The funding sources were not directly involved in the design and conduct of the study; collection, management, analysis, and interpretation of the data; preparation, review, and approval of the manuscript; or decision to submit the manuscript for publication.

Author Contributions: B.D.H. was responsible for study conception and design, data analysis, and manuscript drafting and critical revision of the manuscript for important intellectual content. M.G.F., R.B., F.J., and B.J.M. were responsible for data acquisition as well as critical revision of the manuscript for important intellectual content. P.J.C. and R.S.J.E. were responsible for data collection, data analysis, and critical revision of the manuscript for important intellectual content. E.K.S. and C.P.H. were responsible for study conception and design, data collection, statistical analysis, obtaining funding, and critical revision of the manuscript for important intellectual content.

Correspondence and requests for reprints should be addressed to Craig P. Hersh, M.D., M.P.H., Channing Division of Network Medicine, Brigham and Women's Hospital, 181 Longwood Avenue, Boston, MA 02115. E-mail: craig.hersh@channing.harvard.edu

This article has an online supplement, which is accessible from this issue's table of contents online at www.atsjournals.org

Ann Am Thorac Soc Vol 11, No 9, pp 1387-1394, Nov 2014

Copyright (C) 2014 by the American Thoracic Society

Originally Published in Press as DOI: 10.1513/AnnalsATS.201405-224OC on October 8, 2014

Internet address: www.atsjournals.org 
The epidemiology and mechanisms of pneumothorax have been extensively studied; however, the demographic and quantitative computed tomography (CT) imaging features associated with pneumothorax are not well described, particularly in smokers with chronic obstructive pulmonary disease (COPD). Previous research has focused on describing pneumothorax within the traditional classifications: primary spontaneous, secondary spontaneous, or traumatic (from either iatrogenic or noniatrogenic causes) (1-3).

Primary spontaneous pneumothorax (PSP) occurs in the absence of clinically apparent lung disease $(4,5)$. PSP has been associated with male sex, tall and thin stature, tobacco smoking, and atmospheric pressure changes (5-8). In two case-control studies, the CT scans of persons with recent PSP (including nonsmokers) were found to have significantly more emphysema-like changes in both studies as well as a lower mean radiographic density of the lungs in one of the studies $(9,10)$. A CT study and multiple surgical studies have consistently identified blebs and bullae in patients suffering a spontaneous pneumothorax (11-16). Secondary spontaneous pneumothorax occurs in patients with clinically apparent lung disease, which is most commonly COPD $(2,17,18)$. In COPD, more severe disease with $\mathrm{FEV}_{1}$ less than $1 \mathrm{~L}$ has been reported to be associated with increased risk of developing secondary spontaneous pneumothorax $(1,19)$. The risk of iatrogenic pneumothorax has been associated with the qualitative appearance of emphysema on chest CT scans $(20,21)$. The association of iatrogenic pneumothorax with spirometry values is not clear, as two studies have showed inconsistent results $(21,22)$.

We sought to explore the epidemiologic, spirometric, and chest CT imaging features associated with pneumothorax within the COPD Genetic Epidemiology (COPDGene) Study, a large population of smokers with a broad range of lung function values, to evaluate factors associated with a history of pneumothorax, particularly in smokers with COPD. A better understanding of the difference in risk factors associated with a history of pneumothorax in patients with COPD compared with persons with normal spirometry is especially important given the higher morbidity of pneumothorax in the
COPD population. We hypothesized that in a population of smokers including patients with COPD, a history of pneumothorax would be associated with male sex, tall and thin stature, increased smoking exposure, more severe airflow obstruction, and a greater percentage of emphysema on CT scan. In addition, we hypothesized that quantitative CT measures of pleural-based emphysema would be associated with a history of pneumothorax.

\section{Methods}

\section{Subject Selection}

The COPDGene Study is an observational study that was developed to identify the genetic and epidemiologic factors contributing to the development of COPD and its subtypes. The study was conducted at 21 study centers across the United States (ClinicalTrials.gov identifier NCT00608764); institutional review board approval was obtained at each center, and participants provided written informed consent. In brief, the study included nonHispanic white and African American subjects between the ages of 45 and 80 years with a minimal smoking history of 10 packyears. Individuals with a history of lung disease other than COPD or asthma, surgical excision of at least one lobe of the lung, or lung volume reduction surgery were excluded. Full details of the study design including inclusion and exclusion criteria have been previously described and are available online at www.COPDGene.org (23).

The March 12, 2013 COPDGene data set was used $(n=10,192)$. After exclusions for missing CT data $(n=1,130)$, we included 9,062 individuals.

\section{Chest CT Imaging}

Quantitative analysis of inspiratory CT scans was performed with 3D Slicer software (http://airwayinspector.acil-bwh.org/) (24). Percent emphysema on inspiratory CT was defined as the fraction of lung with attenuation below -950 Hounsfield units (HU) (25). Expiratory scans were performed in 7,094 participants; gas trapping was quantified as the percentage of lung on expiratory CT scan with attenuation below $-856 \mathrm{HU}(26,27)$. Quantitative CT airway measurements including square root of airway wall area at hypothetical $10-\mathrm{mm}$ internal diameter airways (Pi10) and wall area percentage of segmental airways were obtained with VIDA software (VIDA Diagnostics, Inc, Coralville, IA) $(28,29)$.

Additional quantitative CT analysis included classification of emphysema pattern based on local histogram information; the method for generating local histogram-based quantitative emphysema patterns in the COPDGene Study has been previously defined $(30,31)$. On the basis of a set of expert-defined training images, an algorithm was developed to classify each lung region into one of six categories according to emphysema pattern: normal; mild, moderate, or severe centrilobular emphysema; panlobular emphysema; or pleural-based emphysema. Pleural-based emphysema was defined as emphysema that abutted the chest wall. For each CT scan, the six categories of local histogram emphysema pattern are expressed as a fraction of total lung volume represented by each category of emphysema (30).

\section{Spirometry}

All COPDGene participants underwent spirometry before and after inhaled albuterol. COPD was defined by postbronchodilator $\mathrm{FEV}_{1} / \mathrm{FVC}$ less than 0.7 and $\mathrm{FEV}_{1}$ less than $80 \%$ predicted, corresponding to Global Initiative for Chronic Obstructive Lung Disease (GOLD) spirometry stages $2-4$ (32).

\section{Identification of Pneumothorax Cases}

The study questionnaire asked, "Have you ever been told by a physician that you have pneumothorax (collapsed lung)?" The answer was recorded as "no" if the subject responded no or if they did not know. The date and circumstances of the pneumothorax were not captured in the questionnaire. To validate patients' reports of pneumothorax, a medical record review was performed at three COPDGene clinical centers (Morehouse School of Medicine, Atlanta, GA; National Jewish Health, Denver, CO; and Brigham and Women's Hospital, Boston, MA).

\section{Statistical Analysis}

All analyses were conducted in $\mathrm{R}$ version 3.1.1 (33). Univariate analysis used chisquared tests, two-tailed $t$ tests, and Wilcoxon rank-sum tests. A multivariable logistic regression model was constructed with history of pneumothorax as the 
outcome variable. Covariates included sex, race, height, weight, age of study enrollment, pack-years of smoking, $\mathrm{FEV}_{1}$, percent emphysema on CT, ratio of upper to lower one-third lung percent emphysema on CT, and TLC calculated by CT. Regression analysis using the abovecited models was performed in all subjects and in two subgroups including study participants with normal spirometry $\left(\mathrm{FEV}_{1} / \mathrm{FVC}\right.$ ratio $>0.7$ and $\mathrm{FEV}_{1} \geqslant 80 \%$ predicted) as well as study participants with COPD (GOLD spirometry stages 2-4).

Additional regression models were constructed with local histogram pleuralbased emphysema and with gas-trapping independently added to the above-cited model. Regression diagnostics are described in the online supplement.

Some of the results of this study have been previously reported in the form of an abstract at the American Thoracic Society 2014 International Conference (34).

\section{Results}

Of the 9,062 participants, 286 (3.2\%) reported a history of pneumothorax. In validating patient reports of pneumothorax, a medical record review at three study centers confirmed a pneumothorax was documented in the medical record for 25 (74\%) of 34 participants. Compared with participants without a history of pneumothorax, the 286 participants reporting a history of pneumothorax were more commonly male ( $61.5 \%$ vs. $54.0 \%)$, more commonly non-Hispanic white (79.4\% vs. $66.9 \%$ ), had a higher average pack-year smoking history, started smoking at a younger age, and had significantly lower values of $\mathrm{FEV}_{1}$ percent predicted, FVC percent predicted, and $\mathrm{FEV}_{1} / \mathrm{FVC}$ ratio (Table 1). Corresponding to the lower average $\mathrm{FEV}_{1}$ levels, the participants reporting a history of pneumothorax more often had a diagnosis of COPD by GOLD criteria. Moreover, a higher percentage of participants with severe to very severe COPD (GOLD spirometry stage 3 or 4 ) reported a history of pneumothorax compared with participants with mild to moderate COPD (GOLD spirometry stage 1 or 2$)(6.0 \%$ vs. $4.1 \%$; $P=0.006)$. A higher proportion of participants without a history of pneumothorax had normal spirometry ( $44.7 \%$ vs. $24.1 \%)$ or preserved ratio with impaired spirometry (PRISm), defined as

Table 1. Clinical and demographic features of COPDGene Study participants with and without a history of self-reported pneumothorax

\begin{tabular}{|c|c|c|c|}
\hline \multirow[t]{2}{*}{ Subject Characteristic } & \multicolumn{2}{|c|}{ History of Pneumothorax? } & \multirow[b]{2}{*}{$P$ Value* } \\
\hline & Yes $(n=286)$ & No $(n=8,776)$ & \\
\hline Males, \% & $176(61.5)$ & $4,737(54)$ & 0.01 \\
\hline Age at enrollment, yr & $61.5 \pm 8.8$ & $59.5 \pm 9.0$ & 0.0002 \\
\hline Non-Hispanic white, \% & $227(79.4)$ & $5,869(66.9)$ & - \\
\hline African American, \% & 59 (20.6) & 2,907 (33.1) & $\overline{\mathrm{nan}}{ }^{\dagger}$ \\
\hline Height, cm & $171 \pm 9.6$ & $170 \pm 9.5$ & 0.4 \\
\hline Weight, kg & $82.6 \pm 20.2$ & $83.6 \pm 19.5$ & 0.4 \\
\hline Pack-years smoking & $50.7 \pm 25.7$ & $44.1 \pm 24.8$ & $<0.0001$ \\
\hline Age started smoking & $16 \pm 4.3$ & $16.9 \pm 4.7$ & 0.0003 \\
\hline Education, some college vs. no college, \% & $172(60.1)$ & $5,371(61.2)$ & 0.8 \\
\hline PRISm, $\neq \%$ & $26(9.1)$ & $1,073(12.2)$ & - \\
\hline Normal spirometry, \% \% & $69(24.1)$ & $3,920(44.7)$ & - \\
\hline GOLD 1, \% & $36(12.6)$ & $699(8.0)$ & - \\
\hline GOLD 2, \% & $64(22.4)$ & 1,666 (19.0) & - \\
\hline GOLD 3, \% & $59(20.6)$ & $956(10.9)$ & - \\
\hline \multirow[t]{2}{*}{ GOLD $4, \%$} & $32(11.2)$ & $462(5.3)$ & - \\
\hline & - & - & $<0.0001^{\|}$ \\
\hline $\mathrm{FEV}_{1}, \%$ predicted & $67 \pm 28$ & $77 \pm 25$ & $<0.0001$ \\
\hline FVC, \% predicted & $85 \pm 21$ & $88 \pm 18$ & 0.03 \\
\hline $\mathrm{FEV}_{1} / \mathrm{FVC}$ & $0.59 \pm 0.18$ & $0.67 \pm 0.16$ & $<0.0001$ \\
\hline
\end{tabular}

Definition of abbreviations: COPDGene = COPD Genetic Epidemiology; GOLD = Global Initiative for Chronic Obstructive Lung Disease.

Data are shown as number (\%) or mean \pm standard deviation.

${ }^{*} t$ test for quantitative variables. Chi-squared test for categorical variables.

tProbability value refers to race data.

${ }^{\ddagger} \mathrm{PRISm}=$ preserved ratio impaired spirometry, that is, $\mathrm{FEV}_{1} / \mathrm{FVC}$ ratio $\geqslant 0.7$, with reduced $\mathrm{FEV}_{1}$ and $/$ or FVC $<80 \%$ (35).

$\mathrm{S}_{\mathrm{FEV}} / \mathrm{FVC}$ ratio $\geqslant 0.7$ and $\mathrm{FEV}_{1} \geqslant 80 \%$ predicted.

"Probability value refers to PRISm, spirometry, and GOLD data.

$\mathrm{FEV}_{1} / \mathrm{FVC}$ ratio of at least 0.7 with reduced $\mathrm{FEV}_{1}$ and/or FVC less than $80 \%$ predicted (12.2\% vs. 9.1\%) (35). Characteristics of study participants with normal spirometry and with COPD are shown in Tables E1 and E2 in the online supplement.

Participants who reported a history of pneumothorax had a significantly higher percentage of emphysema on chest CT scan (11.5\% vs. $5.9 \%$; Table 2 ). In addition, participants reporting a history of pneumothorax had an increased ratio of percent emphysema in the upper one-third of the lungs compared with the lower one-third of the lungs on CT scan (Table 2). Participants with a history of pneumothorax had larger CT-calculated TLC (5.9 L vs. $5.5 \mathrm{~L}$ ). There was no difference between participants with and without a history of pneumothorax when comparing airway wall thickness measured at Pi10 or the wall area percentage of segmental airways.

Multivariable logistic regression analysis was employed on the entire study population as well as two subgroups: participants with normal spirometry and participants with COPD (Table 3). In all participants, risk of prior pneumothorax was significantly higher in men (odds ratio [OR], 1.55; 95\% confidence interval [CI], 1.08-2.22) and non-Hispanic white subjects (OR, 1.90; 95\% CI, 1.34-2.69). Past pneumothorax risk was associated with increased percent emphysema on CT scan (OR, 1.04 for each 1\% increase in emphysema; 95\% CI, 1.03-1.06) and was inversely associated with TLC (OR, 0.87 for each 1-L increase; 95\% CI, 0.76-1.00).

In participants with normal spirometry, risk of past pneumothorax was associated with increased smoking history (OR, 1.20 for every 10 pack-year increase in smoking; 95\% CI, 1.09-1.33) and nonHispanic white race $(\mathrm{OR}, 2.12$; 95\% CI, 1.10-4.09). In contrast, in participants with COPD, risk of previous pneumothorax was associated with increased percent emphysema on CT scan (OR, 1.04 for each $1 \%$ increase; $95 \% \mathrm{CI}, 1.03-1.06)$ and was inversely associated with TLC (OR, 0.72 for each 1-L increase in TLC; $95 \% \mathrm{CI}$, 
Table 2. Chest computed tomography variables in COPDGene Study participants with and without pneumothorax: univariate analysis

\begin{tabular}{|c|c|c|c|}
\hline \multirow[t]{2}{*}{ CT Variable } & \multicolumn{2}{|c|}{ History of Pneumothorax? } & \multirow[b]{2}{*}{$P$ Value* } \\
\hline & Yes $(n=286)$ & No $(n=8,776)$ & \\
\hline Percent emphysema (\%LAA -950 HU) ${ }^{\dagger}$ & $11.5 \pm 13.7$ & $5.9 \pm 9.3$ & $<0.0001$ \\
\hline $\begin{array}{l}\text { Ratio of percent emphysema in upper } \\
\text { one-third to lower one-third of lungs } \\
\text { on CT scan }\end{array}$ & $2.9 \pm 7.5$ & $2.0 \pm 8.9$ & $<0.0001$ \\
\hline Total lung capacity $(\mathrm{L})$ by CT scan & $5.9 \pm 1.5$ & $5.5 \pm 1.4$ & $<0.0001$ \\
\hline Square root airway wall area at $\mathrm{Pi} 10$ & $3.7 \pm 0.1$ & $3.7 \pm 0.1$ & 0.2 \\
\hline Wall area percent for segmental airways & $61.6 \pm 3.2$ & $61.4 \pm 3.2$ & 0.3 \\
\hline
\end{tabular}

Definition of abbreviations: $\mathrm{CT}=$ computed tomography; $\mathrm{HU}=$ Hounsfield units; $\mathrm{LAA}=$ lung area with attenuation; Pi10 = 10-mm internal diameter airway.

Data represent means \pm standard deviation.

${ }^{\star} P$ values were determined using $t$ tests for normally distributed data and Wilcoxon rank-sum tests for nonparametric data.

t\%LAA $-950 \mathrm{HU}$, the percentage of lung area with attenuation less than $-950 \mathrm{HU}$.

0.59-0.87). We examined the interaction term between emphysema and TLC and this was not significant when added to our multivariable model. Figure 1 illustrates the increase in the percentage of participants with COPD who reported a history of pneumothorax, when participants are divided into groups according to percent emphysema on CT scan.

Because different models of CT scanners were used at different COPDGene study centers, we adjusted for CT scanner type without significant improvement in the logistic regression model performance, so the reported results do not include CT scanner type as a covariate.

When a local histogram-based measure of subpleural emphysema was added to our regression model, subpleural emphysema was significantly associated with pneumothorax (OR, 1.05 for each 1\% increase in subpleural emphysema; 95\% CI, 1.01-1.1), even after accounting for total CT emphysema as quantified by the percentage of lung area with attenuation less than -950 HU (\%LAA -950). The local histogram measure of subpleural emphysema was not associated with pneumothorax in participants with normal spirometry or COPD (Table 4).

Several authors have proposed that gas trapping and local hyperinflation may lead to regional pressure differences in the distal alveoli with subsequent lung parenchymal disruption resulting in pneumothorax (36, 37). We built a separate logistic regression model using the subgroup of 7,094 participants with expiratory CT scans available. When added as a covariate to the regression models displayed in Table 3 , percent gas trapping was not independently associated with the occurrence of pneumothorax.

\section{Discussion}

Pneumothorax is a clinically important condition, often leading to hospitalization (38). Persons with COPD suffering a spontaneous pneumothorax are at risk for increased morbidity compared with persons without COPD $(1,2)$. Among all smokers, the present study noted increased risk of previous pneumothorax to be associated with male sex, non-Hispanic white race, increased percent emphysema, and smaller TLC in a multivariable model. The current study is novel regarding the large sample size with inclusion of a large percentage of African American participants.

Table 3. Logistic regression predictors of pneumothorax in all study participants, participants with normal spirometry, and participants with chronic obstructive pulmonary disease

Multivariable Predictor

Sex, male
Race, non-Hispanic white
Weight, kg
Height, cm
Age at enrollment
Smoking history, per 10 pack-years
FEV ${ }_{1}, \mathrm{~L}$
Percent emphysema on CT scan
Ratio of percent emphysema in upper
one-third to lower one-third of lungs
on CT scan
Total lung capacity (L) by CT scan

\begin{tabular}{c} 
All Participants \\
(PTX $=286$, without \\
PTX = 8,776) \\
\hline Odds \\
Ratio $\quad 95 \%$ Cl $\quad P$ Value
\end{tabular}

$\begin{array}{lll}\mathbf{1 . 5 5} & \mathbf{1 . 0 8 - 2 . 2 2} & \mathbf{0 . 0 2} \\ \mathbf{1 . 9 0} & \mathbf{1 . 3 4 - 2 . 6 9} & \mathbf{0 . 0 0 0 3} \\ 1.00 & 0.99-1.01 & 0.6 \\ 1.00 & 0.98-1.03 & 0.7 \\ 0.99 & 0.98-1.01 & 0.4 \\ 1.05 & 1.00-1.09 & 0.06 \\ 0.92 & 0.75-1.12 & 0.4 \\ \mathbf{1 . 0 4} & \mathbf{1 . 0 3 - 1 . 0 6} & <\mathbf{0 . 0 0 0 1} \\ 1.00 & 1.00-1.01 & 0.2\end{array}$

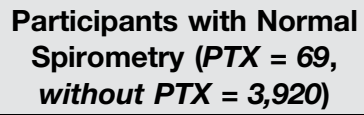

1.10

\subsection{0}

2.12

0.99

1.02

0.97

1.20

0.99

1.02

1.00
$95 \%$ Cl

$0.52-2.34$

1.10-4.09

$0.98-1.01$

$0.97-1.07$

$0.93-1.01$

1.09-1.33

$0.46-2.13$

$0.93-1.12$

0.98-1.02

3,920)
$P$ Value

$P$ Value

0.8
0.03
0.4
0.5
0.09
0.0002
1.0
0.6
1.0

0.87
$0.76-1.00 \quad 0.04$

0.98

$0.71-1.35$

0.9

\subsection{2}

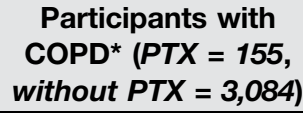

Participants with COPD* $(P T X=155$, without $P T X=3,084$ )

Odds

Ratio $\quad 95 \%$ Cl $P$ Value

$1.64 \quad 1.00-2.71 \quad 0.052$

$\begin{array}{lll}1.62 & 0.99-2.64 & 0.054\end{array}$

$\begin{array}{lll}1.00 & 0.99-1.01 & 0.7\end{array}$

$\begin{array}{lll}1.02 & 0.99-1.05 & 0.3\end{array}$

$0.99 \quad 0.97-1.01 \quad 0.2$

$\begin{array}{lll}1.00 & 0.94-1.06 & 1.0\end{array}$

$0.94 \quad 0.65-1.37 \quad 0.8$

$1.04 \quad 1.03-1.06<0.0001$

$1.01 \quad 1.00-1.01 \quad 0.3$

Definition of abbreviations: $\mathrm{Cl}$ = confidence interval; COPD = chronic obstructive pulmonary disease; CT = computed tomography; PTX = pneumothorax Statistically significant predictors are shown in boldface.

${ }^{*} \mathrm{FEV}_{1} / \mathrm{FVC}$ ratio $<0.7$ and $\mathrm{FEV}_{1}<80 \%$ predicted (GOLD stages $\left.2-4\right)$. 


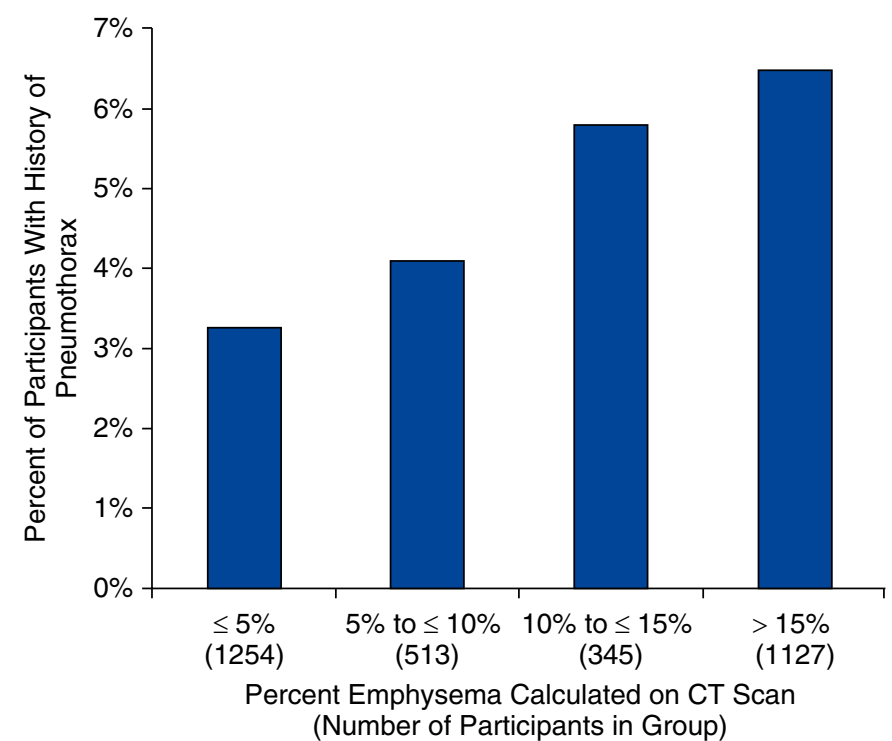

Figure 1. Percentage of participants with chronic obstructive pulmonary disease reporting history of pneumothorax, separated by percent emphysema on computed tomography (CT) scan.

Although the association of pneumothorax with male sex has been previously described, previous studies have not identified non-Hispanic white race to be associated with pneumothorax (6). The association of pneumothorax history with non-Hispanic white race was significant among all participants and smokers with normal spirometry. The association of pneumothorax with non-Hispanic white race approached significance in the study participants with COPD. The association of non-Hispanic white race with pneumothorax might be attributed to differences in overall severity of airflow obstruction and emphysema in nonHispanic white individuals compared with African Americans in the COPDGene Study; however, the persistent association of non-Hispanic white race with pneumothorax in the subgroup of smokers with normal spirometry illustrates that the racial differences in pneumothorax history are unlikely to be solely due to differences in airflow obstruction and emphysema. The association of pneumothorax with non-Hispanic white race may reflect unmeasured confounders, such as differences in socioeconomic status and health care access. However, unlike chronic, largely asymptomatic diseases such as hypertension or type 2 diabetes, pneumothorax is an emergency condition often leading to invasive procedures, and is unlikely to be overlooked due to health care access. Or the racial differences in pneumothorax development may be potentially explained by genetic differences. Unfortunately, our study is underpowered to appropriately evaluate genetic associations with pneumothorax. Further study regarding racial differences in pneumothorax is warranted.

In the subgroup of smokers with normal spirometry, aside from non-

Table 4. Logistic regression predictors of pneumothorax with inclusion of local histogram measure of subpleural emphysema with analysis performed in all study participants, participants with normal spirometry, and participants with chronic obstructive pulmonary disease

\begin{tabular}{|c|c|c|c|c|c|c|c|c|c|}
\hline \multirow[t]{2}{*}{ Multivariable Predictor } & \multicolumn{3}{|c|}{$\begin{array}{c}\text { All Participants } \\
\text { (PTX = 286, without } \\
\text { PTX = 8,776) }\end{array}$} & \multicolumn{3}{|c|}{$\begin{array}{c}\text { Participants with Normal } \\
\text { Spirometry }(P T X=69 \\
\text { without } P T X=3,920)\end{array}$} & \multicolumn{3}{|c|}{$\begin{array}{l}\text { Participants with COPD* } \\
\text { (PTX = 155, without } \\
P T X=3,084)\end{array}$} \\
\hline & $\begin{array}{l}\text { Odds } \\
\text { Ratio }\end{array}$ & $95 \% \mathrm{Cl}$ & $P$ Value & $\begin{array}{l}\text { Odds } \\
\text { Ratio }\end{array}$ & $95 \% \mathrm{Cl}$ & $P$ Value & $\begin{array}{l}\text { Odds } \\
\text { Ratio }\end{array}$ & $95 \% \mathrm{Cl}$ & $P$ Value \\
\hline Sex, male & 1.49 & $1.04-2.14$ & 0.03 & 1.09 & $0.51-2.32$ & 0.8 & 1.57 & $0.95-2.60$ & 0.08 \\
\hline Race, non-Hispanic white & 1.92 & $1.35-2.73$ & 0.0003 & 2.11 & $1.09-4.09$ & 0.03 & 1.67 & $1.02-2.73$ & 0.04 \\
\hline Weight, $\mathrm{kg}$ & 1.00 & $0.99-1.01$ & 1.0 & 0.99 & $0.98-1.01$ & 0.3 & 1.00 & $0.99-1.01$ & 1.0 \\
\hline Height, $\mathrm{cm}$ & 1.00 & $0.98-1.03$ & 0.7 & 1.02 & $0.97-1.07$ & 0.5 & 1.02 & $0.99-1.05$ & 0.3 \\
\hline Age at enrollment & 0.99 & $0.97-1.01$ & 0.3 & 0.97 & $0.93-1.01$ & 0.08 & 0.99 & $0.96-1.01$ & 0.2 \\
\hline Smoking history, per 10 pack-years & 1.04 & $1.00-1.09$ & 0.07 & 1.20 & $1.09-1.33$ & 0.0002 & 1.00 & $0.94-1.06$ & 0.9 \\
\hline $\mathrm{FEV}_{1}, \mathrm{~L}$ & 0.92 & $0.76-1.13$ & 0.4 & 1.00 & $0.46-2.15$ & 1.0 & 0.95 & $0.65-1.38$ & 0.8 \\
\hline Percent emphysema on CT scan & 1.03 & $1.01-1.05$ & 0.01 & 1.00 & $0.88-1.14$ & 1.0 & 1.03 & $1.01-1.06$ & 0.01 \\
\hline $\begin{array}{l}\text { Ratio of percent emphysema in upper } \\
\text { one-third to lower one-third of lungs } \\
\text { on CT scan }\end{array}$ & 1.00 & $1.00-1.01$ & 0.2 & 1.00 & $0.98-1.02$ & 1.0 & 1.01 & $1.00-1.01$ & 0.3 \\
\hline Total lung capacity (L) by CT scan & 0.89 & $0.77-1.02$ & 0.1 & 0.99 & $0.71-1.37$ & 1.0 & 0.74 & $0.61-0.91$ & 0.003 \\
\hline $\begin{array}{l}\text { Local histogram emphysema - percent } \\
\text { subpleural emphysema }\end{array}$ & 1.05 & $1.01-1.10$ & 0.01 & 1.03 & $0.89-1.19$ & 0.7 & 1.04 & $0.99-1.11$ & 0.1 \\
\hline
\end{tabular}

Definition of abbreviations: $\mathrm{Cl}$ = confidence interval; COPD = chronic obstructive pulmonary disease; $\mathrm{CT}=$ computed tomography; PTX = pneumothorax. Statistically significant predictors are shown in boldface.

${ }^{\star} \mathrm{FEV}_{1} / \mathrm{FVC}$ ratio $<0.7$ and $\mathrm{FEV}_{1}<80 \%$ predicted (GOLD stages $2-4$ ). 
Hispanic white race, pack-years of cigarette smoking was associated with a history of pneumothorax. Previous work from Bense and colleagues has demonstrated this relationship and our study supports these earlier findings (5).

Quantitative CT measurements have not been widely used in previous pneumothorax research. The association between CT emphysema and history of pneumothorax in participants with COPD is consistent with prior work describing an increased appearance of emphysema-like changes on chest CT scans of patients with spontaneous pneumothorax $(9,10)$. Our study differs from previous data regarding emphysema and pneumothorax, as we identified an association between increased percent emphysema and pneumothorax in participants with COPD, but not in smokers without COPD. Previous research on risk factors for pneumothorax in patients with COPD has identified $\mathrm{FEV}_{1}$ less than $1 \mathrm{~L}$ to be associated with increased risk of pneumothorax; however, these studies did not clearly evaluate $\mathrm{FEV}_{1}$ effects independent of emphysema $(1,19)$. COPD is a heterogeneous disease composed of both emphysema and airway disease, which are present to a variable degree across similar levels of lung function. Our finding of pneumothorax association with emphysema, but not with $\mathrm{FEV}_{1}$ or airway wall phenotypes, suggests that pneumothorax is more likely to be related to emphysematous subtypes of COPD rather than airway-predominant subtypes of COPD.

The association of pneumothorax with smaller TLC in multivariable models including all participants and in participants with COPD was a surprising finding, because univariate analysis revealed the opposite relationship. It is possible that smaller CT-measured TLC reflects the presence of early interstitial lung disease, which has previously been noted at a $5-10 \%$ prevalence rate in a subset of smokers from the COPDGene Study and has been associated with reduced TLC $(39,40)$. A study by Lippert and colleagues noted that the presence of pulmonary fibrosis on chest X-ray was the single greatest independent risk factor for predicting recurrence after a first episode of PSP (41).

Castaldi and colleagues reported that local histogram measures of emphysema (including centrilobular, panlobular, and pleural-based emphysema patterns) provide novel information relating to respiratory symptoms, complications, and physiology in participants with COPD (31). Given the CT and surgical studies reporting an excess of subpleural blebs and bullae in participants suffering a pneumothorax, we sought a tool for an automated and quantified evaluation of subpleural lung abnormalities. In the entire study population, pleural-based local histogram emphysema was independently associated with pneumothorax and may be picking up a signal of excess peripheral lung field abnormalities contributing to pneumothorax pathogenesis. Visual assessment of all CT scans with scoring of not only the severity of both paraseptal and subpleural emphysema, but also the severity and location of blebs and bullae, would be the most ideal information for detection of differences between participants with and without a history of pneumothorax, but those data are not currently available in COPDGene. However, our current study highlights the ability of local histogram measures of emphysema to provide unique physiological information.

The observational study design has several potential limitations. COPDGene relied on subject recall in reporting past medical history events such as pneumothorax. Therefore, we performed a medical record review in a subset of participants and confirmed that a majority of these participants had a history of pneumothorax confirmed in the medical record. The imperfect medical record validation of patient report of pneumothorax suggests the possibility of misclassification bias. However, one would not expect misclassification of pneumothorax to be related to CT parameters. Such nondifferential misclassification would bias toward the null Despite this, we were still able to discover statistically significant associations with a history of pneumothorax. An additional limitation of our study is the lack of detailed information regarding the timing and etiology of the reported pneumothorax. The lack of temporal information prevents an exact determination of a subject's cumulative tobacco exposure, current smoking status, burden of emphysema, and COPD diagnosis at the time of their pneumothorax. Because of this limitation, we did not make a distinction between primary and secondary pneumothorax in our study. Despite these limitations, we were able to identify demographic as well as CT imaging features associated with a history of pneumothorax in a population of smokers, including persons with COPD.

The results from this study indicate that in all smokers, there is an association between pneumothorax and non-Hispanic white race, male sex, and increased quantity of CT emphysema. In smokers with normal spirometry, the risk of prior pneumothorax increased in a dose-dependent manner with lifetime cigarette smoking history. This study also highlights the association between pneumothorax and increased quantity of CT emphysema in participants with COPD. This is a novel finding, with past research pointing to decreased $\mathrm{FEV}_{1}$ as the predominant risk factor for pneumothorax among patients with COPD. Pleural-based emphysema is independently associated with history of pneumothorax. The identification of the above associations may help to heighten awareness of pneumothorax in similar populations of patients.

Author disclosures are available with the text of this article at www.atsjournals.org.

Acknowledgment: The authors acknowledge and thank the COPDGene Core Teams and Clinical Centers:

\section{COPDGene Investigators: Core Units}

Administrative Core: James Crapo, M.D. (PI), Edwin Silverman, M.D., Ph.D. (PI), Barry Make, M.D., Elizabeth Regan, M.D., Rochelle Lantz, Lori Stepp, Sandra Melanson

Genetic Analysis Core: Terri Beaty, Ph.D., Nan Laird, Ph.D., Christoph Lange, Ph.D., Michael Cho, M.D., Stephanie Santorico, Ph.D. John Hokanson, M.P.H., Ph.D., Dawn DeMeo, M.D., M.P.H., Nadia Hansel, M.D., M.P.H., Craig Hersh, M.D., M.P.H., Peter Castaldi, M.D. M.Sc., Merry-Lynn McDonald, Ph.D., Jin Zhou, Ph.D., Manuel Mattheisen, M.D., Emily Wan, M.D., Megan Hardin, M.D., Jacqueline Hetmanski, M.S., Margaret Parker, M.S., Tanda Murray, M.S.

Imaging Core: David Lynch, M.B., Joyce Schroeder, M.D., John Newell, Jr., M.D., John Reilly, M.D., Harvey Coxson, Ph.D., Philip Judy, Ph.D., Eric Hoffman, Ph.D., George Washko, M.D., Raúl San José Estépar, Ph.D., James Ross, M.Sc., Mustafa Al Qaisi, M.D., Jordan Zach, Alex Kluiber, Jered Sieren, Tanya Mann, Deanna Richert, Alexander McKenzie, Jaleh Akhavan, Douglas Stinson

PFT QA Core, LDS Hospital, Salt Lake City, UT: Robert Jensen, Ph.D.

Biological Repository, Johns Hopkins University Baltimore, MD: Homayoon Farzadegan, Ph.D., 
Stacey Meyerer, Shivam Chandan, Samantha Bragan

Data Coordinating Center and Biostatistics, National Jewish Health, Denver, CO: Douglas Everett, Ph.D., Andre Williams, Ph.D., Carla Wilson, M.S., Anna Forssen, M.S., Amber Powell, Joe Piccoli

Epidemiology Core, University of Colorado School of Public Health, Denver, CO: John Hokanson, M.P.H., Ph.D., Marci Sontag, Ph.D., Jennifer Black-Shinn, M.P.H., Gregory Kinney, M.P.H., Ph.D., Sharon Lutz, M.P.H., Ph.D.

\section{COPDGene Investigators: Clinical Centers}

Veterans Affairs Medical Center, Ann Arbor, MI: Jeffrey Curtis, M.D., Ella Kazerooni, M.D.

Baylor College of Medicine, Houston, TX: Nicola Hanania, M.D., M.S., Philip Alapat, M.D., Venkata Bandi, M.D., Kalpalatha Guntupalli, M.D. Elizabeth Guy, M.D., Antara Mallampalli, M.D., Charles Trinh, M.D., Mustafa Atik, M.D., Hasan Al-Azzawi, M.D., Marc Willis, D.O., Susan Pinero, M.D., Linda Fahr, M.D., Arun Nachiappan, M.D., Collin Bray, M.D., L. Alexander Frigini, M.D., Carlos Farinas, M.D., David Katz, M.D., Jose Freytes, M.D., Anne Marie Marciel, M.D.

Brigham and Women's Hospital, Boston, MA: Dawn DeMeo, M.D., M.P.H., Craig Hersh, M.D., M.P.H., George Washko, M.D., Francine Jacobson, M.D., M.P.H., Hiroto Hatabu, M.D., Ph.D., Peter Clarke, M.D., Ritu Gill, M.D., Andetta Hunsaker, M.D., Beatrice TrotmanDickenson, M.B.B.S., Rachna Madan, M.D.

Columbia University, New York, NY: R. Graham Barr, M.D., Dr.P.H., Byron Thomashow, M.D., John Austin, M.D., Belinda D'Souza, M.D.
Duke University Medical Center, Durham, NC: Neil Maclntyre, Jr., M.D., Lacey Washington, M.D., H. Page McAdams, M.D.

Reliant Medical Group, Worcester, MA: Richard Rosiello, M.D., Timothy Bresnahan, M.D., Joseph Bradley, M.D., Sharon Kuong, M.D., Steven Meller, M.D., Suzanne Roland, M.D.

Health Partners Research Foundation, Minneapolis, MN: Charlene McEvoy, M.D. M.P.H., Joseph Tashjian, M.D.

Johns Hopkins University, Baltimore, MD: Robert Wise, M.D., Nadia Hansel, M.D., M.P.H., Robert Brown, M.D., Gregory Diette, M.D., Karen Horton, M.D.

Los Angeles Biomedical Research Institute at Harbor UCLA Medical Center, Torrance, CA: Richard Casaburi, M.D., Ph.D., Janos Porszasz, M.D., Ph.D., Hans Fischer, M.D., Matt Budoff, M.D.

Michael E. DeBakey VAMC, Houston, TX: Amir Sharafkhaneh, M.D., Charles Trinh, M.D., Hirani Kamal, M.D., Roham Darvishi, M.D., Marc Willis, D.O., Susan Pinero, M.D., Linda Fahr, M.D., Arun Nachiappan, M.D., Collin Bray, M.D., L. Alexander Frigini, M.D., Carlos Farinas, M.D., David Katz, M.D., Jose Freytes, M.D., Anne Marie Marciel, M.D.

Minneapolis VA Health Care System, Minneapolis, MN: Dennis Niewoehner, M.D. Quentin Anderson, M.D., Kathryn Rice, M.D., Audrey Caine, M.D.

Morehouse School of Medicine, Atlanta, GA: Marilyn Foreman, M.D., M.S., Gloria Westney, M.D., M.S., Eugene Berkowitz, M.D., Ph.D.
National Jewish Health, Denver, CO: Russell Bowler, M.D., Ph.D., David Lynch, MB, Joyce Schroeder, M.D., Valerie Hale, M.D., John Armstrong II, M.D., Debra Dyer, M.D., Jonathan Chung, M.D., Christian Cox, M.D.

Temple University, Philadelphia, PA: Gerard Criner, M.D., Victor Kim, M.D., Nathaniel Marchetti, D.O., Aditi Satti, M.D., A. James Mamary, M.D., Robert Steiner, M.D., Chandra Dass, M.D., Libby Cone, M.D.

University of Alabama, Birmingham, AL: William Bailey, M.D., Mark Dransfield, M.D., Michael Wells, M.D., Surya Bhatt, M.D., Hrudaya Nath, M.D., Satinder Singh, M.D.

University of California, San Diego, CA: Joe Ramsdell, M.D., Paul Friedman, M.D.

University of lowa, lowa City, IA: Alejandro Cornellas, M.D., John Newell, Jr., M.D., Edwin J. R. van Beek, M.D., Ph.D.

University of Michigan, Ann Arbor, Ml: Fernando Martinez, M.D., MeiLan Han, M.D., Ella Kazerooni, M.D.

University of Minnesota, Minneapolis, MN: Christine Wendt, M.D., Tadashi Allen, M.D.

University of Pittsburgh, Pittsburgh, PA: Frank Sciurba, M.D., Joel Weissfeld, M.D., M.P.H., Carl Fuhrman, M.D., Jessica Bon, M.D., Danielle Hooper, M.D.

University of Texas Health Science Center at San Antonio, San Antonio, TX: Antonio Anzueto, M.D., Sandra Adams, M.D., Carlos Orozco, M.D., Mario Ruiz, M.D., Amy Mumbower, M.D. Ariel Kruger, M.D., Carlos Restrepo, M.D., Michael Lane, M.D.

\section{References}

1 Sahn SA, Heffner JE. Spontaneous pneumothorax. N Engl J Med 2000; 342:868-874.

2 Baumann MH, Noppen M. Pneumothorax. Respirology 2004;9: 157-164.

3 Haynes D, Baumann MH. Pleural controversy: aetiology of pneumothorax. Respirology 2011;16:604-610.

4 Melton LJ III, Hepper NG, Offord KP. Incidence of spontaneous pneumothorax in Olmsted County, Minnesota: 1950 to 1974. Am Rev Respir Dis 1979;120:1379-1382.

5 Bense L, Eklund G, Wiman LG. Smoking and the increased risk of contracting spontaneous pneumothorax. Chest 1987;92:1009-1012.

6 Primrose WR. Spontaneous pneumothorax: a retrospective review of aetiology, pathogenesis and management. Scott Med J 1984;29: 15-20.

7 Melton LJ III, Hepper NG, Offord KP. Influence of height on the risk of spontaneous pneumothorax. Mayo Clin Proc 1981;56:678-682.

8 Alifano M, Forti Parri SN, Bonfanti B, Arab WA, Passini A, Boaron M, Roche N. Atmospheric pressure influences the risk of pneumothorax: beware of the storm! Chest 2007;131:1877-1882.

9 Lesur O, Delorme N, Fromaget JM, Bernadac P, Polu JM. Computed tomography in the etiologic assessment of idiopathic spontaneous pneumothorax. Chest 1990;98:341-347.

10 Bense L, Lewander R, Eklund G, Hedenstierna G, Wiman LG. Nonsmoking, non- $\alpha_{1}$-antitrypsin deficiency-induced emphysema in nonsmokers with healed spontaneous pneumothorax, identified by computed tomography of the lungs. Chest 1993;103:433-438.

11 Casali C, Stefani A, Ligabue G, Natali P, Aramini B, Torricelli P, Morandi $\mathrm{U}$. Role of blebs and bullae detected by high-resolution computed tomography and recurrent spontaneous pneumothorax. Ann Thorac Surg 2013;95:249-255.

12 Schramel FM, Postmus PE, Vanderschueren RG. Current aspects of spontaneous pneumothorax. Eur Respir J 1997;10:1372-1379.

13 Hazelrigg SR, Landreneau RJ, Mack M, Acuff T, Seifert PE, Auer JE, Magee M. Thoracoscopic stapled resection for spontaneous pneumothorax. J Thorac Cardiovasc Surg 1993;105:389-392; discussion 392-383.

14 Inderbitzi RG, Leiser A, Furrer M, Althaus U. Three years' experience in video-assisted thoracic surgery (VATS) for spontaneous pneumothorax. J Thorac Cardiovasc Surg 1994;107:1410-1415.

15 Nkere UU, Griffin SC, Fountain SW. Pleural abrasion: a new method of pleurodesis. Thorax 1991;46:596-598.

16 Schramel FM, Sutedja TG, Janssen JP, Cuesta MA, van Mourik JC, Postmus PE. Prognostic factors in patients with spontaneous pneumothorax treated with video-assisted thoracoscopy. Diagn Ther Endosc 1995;2:1-5.

17 Guo Y, Xie C, Rodriguez RM, Light RW. Factors related to recurrence of spontaneous pneumothorax. Respirology 2005;10:378-384.

18 Light RW. Management of spontaneous pneumothorax. Am Rev Respir Dis 1993;148:245-248.

19 Light RW, O'Hara VS, Moritz TE, McElhinney AJ, Butz R, Haakenson CM, Read RC, Sassoon CS, Eastridge CE, Berger R, et al. Intrapleural tetracycline for the prevention of recurrent spontaneous pneumothorax: results of a Department of Veterans Affairs cooperative study. JAMA 1990;264:2224-2230.

20 Cox JE, Chiles C, McManus CM, Aquino SL, Choplin RH. Transthoracic needle aspiration biopsy: variables that affect risk of pneumothorax. Radiology 1999;212:165-168.

21 García-Río F, Pino JM, Casadevall J, Gómez L, Atienza JM, DíazLobato $\mathrm{S}$, Villamor J. Use of spirometry to predict risk of 
pneumothorax in CT-guided needle biopsy of the lung. $J$ Comput Assist Tomogr 1996;20:20-23.

22 Vitulo P, Dore R, Cerveri I, Tinelli C, Cremaschi P. The role of functional respiratory tests in predicting pneumothorax during lung needle biopsy. Chest 1996;109:612-615.

23 Regan EA, Hokanson JE, Murphy JR, Make B, Lynch DA, Beaty TH, Curran-Everett D, Silverman EK, Crapo JD. Genetic epidemiology of COPD (COPDGene) study design. COPD 2010;7:32-43.

24 Fedorov A, Beichel R, Kalpathy-Cramer J, Finet J, Fillion-Robin JC, Pujol S, Bauer C, Jennings D, Fennessy F, Sonka M, et al. 3D slicer as an image computing platform for the quantitative imaging network. Magn Reson Imaging 2012;30:1323-1341.

25 Gevenois PA, De Vuyst P, de Maertelaer V, Zanen J, Jacobovitz D, Cosio MG, Yernault JC. Comparison of computed density and microscopic morphometry in pulmonary emphysema. Am J Respir Crit Care Med 1996;154:187-192.

26 Jain N, Covar RA, Gleason MC, Newell JD Jr, Gelfand EW, Spahn JD. Quantitative computed tomography detects peripheral airway disease in asthmatic children. Pediatr Pulmonol 2005;40:211-218.

27 Busacker A, Newell JD Jr, Keefe T, Hoffman EA, Granroth JC, Castro $\mathrm{M}$, Fain S, Wenzel S. A multivariate analysis of risk factors for the air-trapping asthmatic phenotype as measured by quantitative CT analysis. Chest 2009;135:48-56.

28 Nakano Y, Wong JC, de Jong PA, Buzatu L, Nagao T, Coxson HO, Elliott WM, Hogg JC, Paré PD. The prediction of small airway dimensions using computed tomography. Am J Respir Crit Care Med 2005;171:142-146.

$29 \mathrm{Hu}$ S, Hoffman EA, Reinhardt JM. Automatic lung segmentation for accurate quantitation of volumetric X-ray CT images. IEEE Trans Med Imaging 2001;20:490-498.

30 Mendoza CS, Washko GR, Ross JC, Diaz AA, Lynch DA, Crapo JD, Silverman EK, Acha B, Serrano C, Estépar RS. Emphysema quantification in a multi-scanner HRCT cohort using local intensity distributions. Proc IEEE Int Symp Biomed Imaging 2012;2012:474-477.

31 Castaldi PJ, San José Estépar R, Mendoza CS, Hersh CP, Laird N, Crapo JD, Lynch DA, Silverman EK, Washko GR. Distinct quantitative computed tomography emphysema patterns are associated with physiology and function in smokers. Am J Respir Crit Care Med 2013;188:1083-1090.
32 Pauwels RA, Buist AS, Calverley PM, Jenkins CR, Hurd SS, GOLD Scientific Committee. Global strategy for the diagnosis, management, and prevention of chronic obstructive pulmonary disease: NHLBI/WHO Global Initiative for Chronic Obstructive Lung Disease (GOLD) Workshop summary. Am J Respir Crit Care Med 2001;163:1256-1276.

33 R Core Team. R: a language and environment for statistical computing. Vienna, Austria: R Foundation for Statistical Computing; 2013.

34 Hobbs BD, Foreman MG, Bowler RP, Jacobson F, Make BJ, Castaldi PJ, Estépar RSJ, Silverman EK, Hersh CP. Pneumothorax risk factors in smokers with and without chronic obstructive pulmonary disease (COPD) from the COPDGene Study [abstract]. Presented at the American Thoracic Society International Conference. May 16-21, 2014, San Diego, CA. D39: Abstract A5830.

35 Wan ES, Castaldi PJ, Cho MH, Hokanson JE, Regan EA, Make BJ, Beaty TH, Han MK, Curtis JL, Curran-Everett D, et al. Epidemiology, genetics, and subtyping of preserved ratio impaired spirometry (PRISm) in COPDGene. Respir Res 2014;15:89.

36 Lillington GA, Mitchell SP, Wood GA. Catamenial pneumothorax. JAMA 1972;219:1328-1332.

37 Noppen M, Verbanck S, Harvey J, Van Herreweghe R, Meysman M, Vincken W, Paiva M. Music: a new cause of primary spontaneous pneumothorax. Thorax 2004;59:722-724.

38 Bense L, Wiman LG, Jendteg S, Lindgren B. Economic costs of spontaneous pneumothorax. Chest 1991;99:260-261.

39 Washko GR, Lynch DA, Matsuoka S, Ross JC, Umeoka S, Diaz A, Sciurba FC, Hunninghake GM, San José Estépar R, Silverman EK, et al. Identification of early interstitial lung disease in smokers from the COPDGene Study. Acad Radiol 2010;17:48-53.

40 Washko GR, Hunninghake GM, Fernandez IE, Nishino M, Okajima Y, Yamashiro T, Ross JC, Estépar RS, Lynch DA, Brehm JM, et al.; COPDGene Investigators. Lung volumes and emphysema in smokers with interstitial lung abnormalities. N Engl J Med 2011;364: 897-906.

41 Lippert HL, Lund O, Blegvad S, Larsen HV. Independent risk factors for cumulative recurrence rate after first spontaneous pneumothorax. Eur Respir J 1991;4:324-331. 